\title{
EN LOS CONFINES DEL OLVIDO DE SÍ: CIENCIA Y TÉCNICA EN LA CRÍTICA CULTURAL DE Michel HENRY AL MUNDO CONTEMPORÁNEO
}

\section{IN THE BOUNDARIES OF SELF-OBLIVION: SCIENCE AND TECHNOLOGY IN MICHEL HENRY'S CULTURAL CRITICISM OF THE CONTEMPORARY WORLD}

\author{
JAIME LLORENTE CARDO \\ I.E.S “C. de Calatrava \\ jakobweinendes@gmail.com
}

\author{
RECIBIDO: 09/02/2018 \\ ACEPTADO: 18/07/2018
}

Resumen: El presente artículo trata de mostrar los aspectos clave de la crítica dirigida a la cultura moderna por el fenomenólogo francés Michel Henry. Se examina fundamentalmente el modo en el que tal crítica intuye tras el desarrollo de la ciencia y la técnica en las sociedades contemporáneas un larvado deseo de huir de sí misma por parte de la subjetividad viviente. Ciencia y técnica aparecen, desde esta perspectiva, como instrumentos "objetivos" creados por la subjetividad, pero cuya principal función consiste paradójicamente en favorecer ese olvido del "sí mismo" individual que define por igual al capitalismo y al comunismo.

Palabras clave: Henry, cultura, ciencia, técnica, vida, subjetividad viviente.

\begin{abstract}
The present work tries to show the key aspects of the criticism adressed to modern culture by the french phenomenologist Michel Henry. It is examined principally the way in which such criticism intuits a hidden wish to escape from itself by the living subjectivity behind the development of science and technology in contemporary societies. Science and technology appear, seen from this point of view, as "objective" tools created by subjectivity, but whose main role consists paradoxically in favouring that oblivion of the individual "self" that is equally characteristic of capitalism and communism.
\end{abstract}

Keywords: Henry, culture, science, technology, life, living subjectivity.

\section{Introducción: cultura y vida}

Al margen de su estricto quehacer fenomenológico, aunque en estrecha vinculación con las tesis fundamentales que conforman su "fenomenología de la vida", el pensador francés Michel Henry desarrolla una radical y contundente crítica dirigida contra la línea de flotación misma de la cultura contemporánea. Esta labor crítica cristaliza fundamentalmente en dos obras: La barbarie, aparecida en 1988, y $D u$ communisme au capitalisme. Théorie $d^{\prime}$ une catastrophe, publicada dos años más tarde que la anterior. En ambos trabajos, el 
fenomenólogo francés toma como hilo conductor de su meditación crítica acerca del mundo moderno la idea de la subjetividad trascendental idéntica a la vida inmanente que se afecta antes que nada a sí misma. Una subjetividad viviente entendida como esencia última y genuina de "eso que verdaderamente somos". Esa vida auto-afectada en su inmediatez patética constituye la esencia misma de la inmanencia que define a la subjetividad en cuanto tal, no admitiendo, por tanto, ser identificada con la vida "material" que cae en el interior de la esfera de los fenómenos tematizados por la biología. ${ }^{1}$ Muy al contrario, la vida trascendental, fenomenológica, de la cual habla Henry no se encuentra en ámbito alguno perteneciente a la exterioridad del mundo objetivo, sino que se identifica con la vida interna, afectada y sentiente que todo individuo humano conoce de forma inmediata, puesto que constituye, en último término, su ser más constitutivamente propio e íntimo. La vida se afecta y experimenta a sí misma en cada viviente particular y ese acto originario de auto-afección constituye precisamente el decisivo rasgo que la define en su esencia. Aquello que contiene en sí la capacidad de auto-afectarse admite por ello mismo ser reconocido como algo vivo, mientras que lo que carece de esta posibilidad (todo lo perteneciente a la exterioridad del mundo objetivo) y simplemente es "afectado" desde el exterior, es inversamente mera facticidad desprovista de vida. ${ }^{2}$ Así, el universo de la exterioridad objetual aparece, contemplado a esta luz, como el reino de la muerte, mientras que la esfera de la pura interioridad subjetiva trascendental se revela a sí misma en términos de auténtico dominio de lo vital.

Desde la perspectiva adoptada por Henry, toda cultura es esencialmente y en virtud de su misma esencia "una cultura de la vida", dado que ésta constituye simultáneamente el sujeto actuante presente en toda forma cultural y el objetivo al que esa actividad vital se dirige. El télos sobre el cual incide y revierte de modo necesario. El concepto de "cultura" mienta, pues, fundamentalmente el movimiento merced al cual la vida subjetiva -individual o colectiva- se modifica

\footnotetext{
${ }^{1}$ A este respecto alude Henry al "Étrange silence de la pensée moderne au sujet de la vie", siempre y cuando se entienda por vie "non la vie biologique composée de molécules et de cellules, qui a ses titres de noblesse galiléens, scientifiques, ses laboratoires, ses crédits, ses chercheurs nombreux et ses débatteurs, mais la vie [...] qui est la vie de tout le monde et dont tout le monde parle, celle des travailleurs notamment mais des oisifs aussi bien" (Henry 2008a, 216).

${ }^{2}$ En referencia a lo esencial de esta "fenomenología de la vida, Paul Audi, en su estudio monográfico sobre el pensamiento de Henry, escribe pertinentemente: "Or, quelque chose qui ne sort jamais de soi, quelque chose qui demeure constamment en lui-même et pour lui-même, quelque chose qui trouve par lui-même de quoi être pleinement ce qu'il est, sans avoir besoin pour cela d'autre chose que de soi, cela porte un nom en philosophie; cela s'appelle l'absolu [...], l' expérience de l'absolu, telle qu' Henry l'entend, consiste à faire en soi l'épreuve de l'immanence. La philosophie de Michel Henry est une phénoménologie de la vie subjective absolue, et cette vie subjective absolue est une vie immanente" (Audi 2006, 31-32).
} 
y altera a sí misma con el fin de desplegarse hacia modos de auto-realización dotados progresivamente de un más elevado volumen de intensidad, altura y desarrollo. En tanto que proceso incesante de consumación y explicitación de sí, la vida se identifica con la propia cultura que propicia tal desenvolvimiento hasta el punto de llevar a ésta ínsita en su seno, bien sea de forma potencial o actual. La esencia de la vida y la de la cultura se muestran, pues, al decir de Henry, como idénticas. Es precisamente esta postulada identidad original entre cultura y vida la que permite emprender un discurso crítico dirigido a la cultura moderna. Una cultura nacida de la revolución instituida por la ciencia galileana y consumada por la matematización cartesiana de la misma, en la cual se instituye una fatal cesura que escinde el ámbito de lo vital de la esfera de la exterioridad objetiva del mundo otorgando preeminencia a la segunda sobre el primero. Este orden de prelación en virtud del cual la objetividad mundana -es decir, el dominio de lo muerto carente de auto-afección- se erige como referente último de todo auténtico saber y todo verdadero experimentar en detrimento de la vida que se siente a sí misma, es instituido por el discurso científico surgido en el instante inaugural de la modernidad.

Tal discurso supone el triunfo de un modo de pensamiento y de un tipo de saber que excluye de la esfera del conocimiento no solamente la totalidad del futuro "mundo de la vida" o Lebenswelt husserliano, sino la propia vida absoluta inmanente en la que consiste el ser más profundo de la subjetividad humana. Ahora bien, si el rasgo capital de toda cultura radica en propiciar el autodesenvolvimiento de la vida y en coadyuvar a su realización efectiva, una cultura dominada por la preeminencia de la objetividad científica ha de dar necesariamente la espalda a la esencia misma de la cultura. ${ }^{3}$ En efecto, al decir henryano, la ciencia carece de relación alguna con la cultura en la medida en que adolece de falta de vinculación esencial con la vida trascendental que esencialmente somos. Y es justamente por esta razón que el progreso científico no guarda relación proporcional alguna con el desarrollo cultural. Esto es precisamente lo que sucede en el marco del mundo tecno-científico contemporáneo en el cual la hipertrofia de la objetividad propia de la ciencia se conjuga con el progresivo marasmo de la genuina actividad cultural. De hecho, los progresos efectuados por ambas instancias mantienen entre sí una relación de proporcionalidad inversa: cuanto más pujante es la potencia del saber científico y del dispositivo técnico emanado de éste, más exangüe deviene el vigor con el que

\footnotetext{
${ }^{3}$ Como apunta en este sentido García Jarama: "Dado que las diversas expresiones de la cultura -de entre las cuales Henry destaca siempre, como su máxima expresión, el arte, la ética y la religióntienen su raíz profunda y constitutiva en la esencia de la vida, al ser la Barbarie la eliminación o la ignorancia de aquellas, también lo será de ésta” (García Jarama 2007, 276).
} 
la cultura es capaz de vivificar el despliegue de las potencias vitales individuales. La hipertrofia de la ciencia supone, por tanto, la atrofia de la cultura, y en esta consunción de la vitalidad cultural es donde reside la raíz última de aquello que Henry designa mediante el término "barbarie". Una barbarie que, de todas formas, lejos de constituir un aciago evento histórico más o menos contingentemente dado, arraiga en el propio núcleo vital del que emana toda cultura, es decir, constituye, según Henry, "una enfermedad de la vida misma" (Henry 2006, 39). Esta enfermedad consiste fundamentalmente en el gradual anquilosamiento de todas las dimensiones propiamente "humanas", esto es, subjetivo-vitales (estéticas, religiosas, éticas, etc.), en el contexto de la objetividad social. Un fenómeno que resulta tanto más sorprendente cuando el origen último de esta degradación y esclerosis hay que ir a buscarlo en el ámbito de una inmanencia subjetiva cuyo acrecentamiento resulta inseparable del brío de la cultura.

Dicha enfermedad espiritual consistente en el decrecimiento del individuo, en el olvido de sí por parte de la subjetividad vital absoluta, no es exclusiva, como pudiera pensarse, de la civilización tecno-científica propia del capitalismo avanzado, sino que afecta igualmente a los modos de organización sociopolítica formalmente opuestos a éste, es decir, a los regímenes comunistas teóricamente herederos de la doctrina marxista. ${ }^{4}$ También en ellos cabe apreciar la sustitución del predominio de la subjetividad viviente por un universo de abstracciones ajenas por completo a la vida individual concreta: "la clase", "el estado", "el partido", "la sociedad", "la historia", etc. ${ }^{5}$ Tales abstracciones se corresponden puntualmente, desde el punto de vista de la individualidad viviente, con aquellas en las cuales se fundamenta la estructura misma del sistema capitalista, esto es, con abstracciones muertas tales como "el valor", "el dinero", "el capital", "el beneficio" o "el interés": "Son estas abstracciones y sus múltiples variables las que han reemplazado a los individuos vivientes, sus deseos, sus pasiones, sus necesidades profundas. De aquí en adelante, son leyes distintas a las de la vida las que conducen el mundo" (Henry, 2008, 23).

De este modo, comunismo y capitalismo coinciden paradójicamente en un rasgo fundacional esencial, a saber: la voluntad de eliminación de la

\footnotetext{
${ }^{4}$ Sobre la particular interpretación "no marxista" que Henry lleva a cabo acerca del pensamiento de Marx, véase: Domínguez Basalo 1982-1983.

5 "Aquello que caracteriza al marxismo desde el punto de vista teórico, es la sustitución de los individuos vivientes por un cierto número de entidades abstractas a partir de las cuales pretende explicar la totalidad de los fenómenos económicos, históricos y sociales y, finalmente, esos individuos mismos. Así, se efectúa un extraordinario vuelco del orden de las cosas al término del cual el principio, el individuo viviente, se convierte en la consecuencia de las abstracciones que han tomado su lugar" (Henry 2008a, 51-52). Las traducciones son del autor.
} 
individualidad viviente particular y aun de la vida subjetiva misma tout court. $^{6}$ Este y Oeste constituyen ambos, pues, cuando son considerados desde el prisma de observación de la individualidad viva, otras tantas "figuras de la muerte". Regímenes que se identifican a la hora de arrumbar la concreta subjetividad viviente a favor de abstracciones objetivas desprovistas de auténtica savia vital. Estas abstracciones son, por lo demás, elementos engendrados por una subjetividad a la cual remiten permanentemente, pero en su condición de objetos de pensamiento no dejan de constituir instancias desprovistas de vida que no se experimentan ni afectan a sí mismas. Objetos ideales que carecen de la capacidad de auto-afección que define esencialmente a todo lo vivo. Los regímenes comunistas edificados sobre esas abstracciones que desconocen por completo la ley de placer/displacer que rige sobre todo viviente, no pueden mostrarse sino como lo que son: "regímenes de muerte". ${ }^{7}$ Del mismo modo que lo son aquellos otros regímenes tecno-capitalistas dominados por la pulsión tendente al logro de la objetividad científica y por la voluntad de maximización económica universal. Ambos hallan su larvada y secreta afinidad en el hecho de cifrar su cimentación última en la referencia a abstracciones muertas absolutamente ajenas a la efectiva individualidad de los vivientes. Y, como sabía bien Aristóteles, la dicha, la desgracia o cualquier otra afección, o bien la experimentan los individuos concretos o no la experimenta nadie en absoluto. Nunca es feliz la pólis, sino únicamente, si acaso, los sujetos individuales y determinados que la pueblan y contribuyen a configurarla; valga este mismo sesgo anti-abstracto a la hora de juzgar el volumen de bienestar de una "clase social" o el "beneficio" obtenido por la sociedad en su conjunto. ${ }^{8}$

Así pues, tanto el capitalismo tardío -presto ya, según Henry, a ser desplazado en cuanto tal por el objetivismo tecno-científico- como el autodenominado "socialismo real" se muestran, a la luz de una fenomenología de la inmanencia radical, como constructos sociopolíticos que se definen merced a

\footnotetext{
${ }^{6}$ Así, escribe Henry, "A los errores teóricos del marxismo corresponde, en el universo triunfante de la técnica, desarrollándose conforme a una temporalidad específica, el mismo proceso monstruoso que arroja al hombre fuera del mundo y al mundo fuera de la vida" (Henry 2008a, 23).

${ }^{7}$ Como apunta al respecto M. Carmen Paredes Martín: "Las grandes abstracciones ideológicas sociedad, historia, clases sociales, proletariado, partido- pretendieron sustituir a los individuos, pero si suprimimos a los individuos no habrá sociedad, ni historia ni clases sociales. La gran contradicción del marxismo, así como del fascismo y de cualquier teoría que quiera suprimir al individuo, es la de negar la vida -aunque, como la vida es lo que define la realidad, tampoco pueden negarla por completo" (Paredes Martín 2010, 112).

${ }^{8}$ Frente a toda tentativa de "abstracción social", Henry postula con explicitud que la vida "no existe más que bajo una forma individual, bajo la forma de individuos vivientes [...], la sociedad no es más que una palabra, o mejor, un concepto para designar una realidad de otro orden: la de los individuos vivientes que constituyen su substancia" (Henry 2008a, 55).
} 
su común exclusión de la subjetividad viviente. Por emplear una expresión del propio Henry, como "imperios de la muerte". ${ }^{9}$ Veamos en lo sucesivo cuáles son las formas y expresiones concretas que esta supresión de lo vital asume en el contexto de la cultura contemporánea, así como sus causas próximas y remotas.

\section{La exclusión de la vida en el universo tecno-científico}

¿Cuál es la razón última por la cual la cultura, aliada y conductora "natural" de la vida, deviene paradójicamente en la época moderna "cultura de lo muerto"? Conforme al dictamen de Henry, el origen de esta inversión teratológica se localiza en el momento histórico en el cual Galileo funda el basamento de la moderna ciencia matemática de la naturaleza. ${ }^{10}$ En efecto, la ciencia galileana se define merced al acto por el cual, en el conocimiento del mundo tal como es en sí mismo al margen de la cambiante multiplicidad de los fenómenos dados a la percepción, se abstraen todas las cualidades ligadas a la subjetividad (particularmente las cualidades sensibles) para dejar subsistir únicamente las estructuras abstractas propias del universo espacio-temporal. Formas abstraídas de la naturaleza realmente percibida que son, además, en lo sucesivo, determinadas conforme a categorías de orden geométrico y matemático entendidas como elementos garantizadores de universalidad, esto es, de validez pretendidamente objetiva para la totalidad de los individuos. Se trata con esto de excluir absolutamente todo atisbo de experiencia individual o de parecer meramente particular de la esfera del conocimiento de lo real tal como ello es

\footnotetext{
${ }^{9}$ En este sentido, Henry indica: "Que se tome, en fin, la medida de un universo del cual he sido excluida la vida. Que ésta haya sido reemplazada por la sociedad, el pueblo, la historia, las clases sociales, por entidades económicas tales como el dinero, el beneficio, el interés y sus respectivas tasas, o, como en la técnica moderna, por la realidad material, es por definición un universo de la muerte. Cuando aquello que no siente nada y no se siente a sí mismo, ni tiene deseo ni amor, es situado al principio de la organización del mundo, llega el tiempo de la locura, pues, en efecto, ha perdido todo salvo la razón" (Henry 2008a, 220).

${ }^{10}$ Henry describe el proceso de tal inversión y sus subsiguientes consecuencias del siguiente modo: "l'exclusion de la subjectivité ne provient pas du capitalisme lui-même mais de la science galiléenne, dont la technique dévoile le véritable sens. Rappelons une dernière fois que la science moderne, inventée par Galilée et visant l'instauration d'une connaissance rationnelle de l'univers, fait abstraction de ses qualités sensibles, et cela parce que cet univers est composé de corps matériels étendus dont les figures et les formes ne peuvent être saisies adéquatement que par la géométrie dont Descartes propose une formulation mathématique. Exclure de l'univers les qualités sensibles, c'est en exclure la sensibilité et avec celle-ci tout ce qui est subjectif et ainsi la vie elle-même" (Henry 2008a, 214).
} 
"en sí mismo", con independencia de aquello que pueda ser "para alguien". ${ }^{11} \mathrm{De}$ este modo, el ámbito de lo subjetivo y de sus contenidos propios (sensaciones, experiencias, padecimientos u opiniones) queda supeditado de forma subsidiaria al universo de la exterioridad objetiva que la ciencia torna visible, y por tanto ha de ser abordado en adelante exclusivamente desde la perspectiva de éste. Aquí radica, al decir henryano, el germen de la dependencia, heteronomía y ulterior disolución de las llamadas "ciencias humanas". Ello se debe a que éstas acaban necesariamente careciendo de "objeto" real de estudio, habida cuenta de que el marasmo infligido a la subjetividad inmanente que habría de constituir su natural correlato por parte del objetivismo científico priva a las tradicionales "ciencias del espíritu" de su método, su sentido y aun de su referente tout court. La llamada "crisis de las humanidades" -cabría aquí hablar directamente de ocaso o de extinción progresiva-, entendida en su significado tanto sociocultural como estrictamente académico, hallaría en esta abstracción originaria de lo subjetivo su causa histórica remota acaso más conspicua.

Todo lo anterior supone el soslayo sistemático de esa inmanencia vital originaria que habita en el núcleo mismo de la subjetividad arrumbada y preterida por el saber científico: único discurso investido de pretensiones cognoscitivas que la "barbarie" propia de la época contemporánea se encuentra dispuesta a acoger y reconocer como legítimo. "La ciencia en cuanto tal [declara explícitamente Henry] no guarda relación alguna con la cultura, y esto porque se desarrolla fuera de la esfera de la propia cultura" (Henry 2006, 41). Pero, si esto es cierto, entonces la ciencia carece igualmente de vínculos esenciales con la vida misma, en tanto que ésta y la cultura constituyen instancias co-originarias e indisociables. En esta carencia de referencia a la subjetividad vital reside de modo embrionario la hipertrofia del objetivismo reduccionista que define, según Henry, la "enfermedad espiritual" propia del mundo contemporáneo y de la cual la tecno-ciencia sería una forma hipostasiada. Y, no obstante, como apunta certeramente Henry, el propio discurso científico que ignora la vida subjetiva

\footnotetext{
${ }^{11}$ A este respecto, Henry aclara: "Bajo la influencia de Demócrito, cuyas ideas se difundían entonces por Europa, Galileo produce en todo caso, en el Saggiatore, el análisis esencial en el cual la ficción descarta todas las propiedades que pueden se efectivamente suprimidas, para hacer aparecer lo invariante sobre lo cual ella se quiebra, designando entonces la esencia [...]. Así es posible conocer el ser-verdadero de la naturaleza e incluso leer, como dice Galileo, en el gran libro del Universo, a condición de conocer la lengua cuyos caracteres son «triángulos, círculos y otras figuras geométricas sin cuyos medios es humanamente imposible comprender una palabra». El genio sin edad de Descartes es el que, retomando y asumiendo la reducción galileana, abre el conocimiento matemático de la naturaleza, es decir, la física y la ciencia modernas, a lograr al mismo tiempo la contrareducción que va a tematizar aquello que la reducción galileana ha puesto fuera de juego y pensarlo hasta el final" (Henry 2015b, 46-47).
} 
original y sus atributos esenciales ha de presuponer siempre, bien sea de forma tácita u oscuramente presentida, esa misma afectividad vital de la cual la propia ciencia surge y en cuya ausencia devendría imposible. Ni siquiera el objetivismo cientificista más irreductiblemente irredento es capaz de abstraer totalmente la esencia de la vida, esto es, "lo que ella experimenta constantemente y de dónde ella saca la motivación escondida, pero invencible, de todo lo que hace" (Henry 2006, 61). Al pretender dar absolutamente la espalda a los intereses vitales del individuo, intereses que jamás se manifiestan en el horizonte externo del mundo objetivo pero que son los únicos realmente existentes, la ciencia reductiva se muestra como un tipo de saber tan abstracto como realmente aislado. Y ello porque incluso la propia abstracción fundacional galileana de las cualidades sensibles propias del mundo natural y su subsiguiente anulación, no deja de mostrarse realmente como un acto llevado a cabo por y desde la misma subjetividad vital que la ciencia a la que tal acto da lugar trata de neutralizar: "Que la ciencia aparte a la vida de su temática, que la desconozca tanto como quiera, no deja por ello de ser una modalidad de esta vida absoluta, a la que pertenece, tanto en su acto inaugural como en cada una de sus fases posteriores" (Henry 2006, 85).

Esta referencia insoslayable de la ciencia a la raíz subjetivo-vital última de la cual se nutre secretamente, pone de relieve el hecho de que la negación del "mundo de la vida" que acontece en el cientificismo moderno constituye realmente una contradicción de la vida consigo misma. Una enfermedad vital inmanente y, por extensión, una monumental discordancia ínsita en el propio seno de la cultura tecno-científica contemporánea. Desde el momento en el que la ciencia ha desechado la totalidad del mundo sensible subjetivo-vital y ha prescindido de él a la hora de fijar su dominio de investigación, el discurso científico se repliega sobre sí en una singularidad absoluta. Se da así la llamativa paradoja consistente en que un discurso que excluye todo Lebenswelt sensible legisla, no obstante, con incondicionada autoridad sobre el mismo ámbito de lo vital y sensible que ella misma ha contribuido decisivamente a minimizar y a suprimir del horizonte teórico de consideración. En referencia a ello, escribe Henry: "Semejante situación, en la que una instancia teórica va a decidir sobre el mundo-de-la-vida y sobre la vida misma sin tenerlos de ninguna manera en cuenta, es lo que caracteriza la fase actual de la historia del mundo, haciendo de ella la Modernidad que -se puede decir- padecemos" (Henry 2006, 67).

De esta contradicción a la que venimos de referirnos participa, asimismo, el fenómeno de la técnica moderna. También en ella se aprecia, al decir de Henry, esa tendencia contranatural a oscurecer la vida originaria mediante un elemento que ha tenido necesariamente que surgir de este mismo 
sustrato vital primigenio. La técnica, producto de la subjetividad viviente en la cual halla su raigambre última, perseguiría, al igual que la ciencia que le sirve de fundamento, el marasmo de aquella mismidad subjetiva de la cual ha surgido y puede únicamente surgir. Parece como si, consciente o inconscientemente, el espíritu propio de la modernidad tratase de librarse de sí mismo mediante la factura de instancias de orden tanto teórico (la ciencia) como práctico (la técnica que deriva de ésta). Contemplada desde esta óptica, la técnica se muestra como una de las más notables consecuencias de la negación (o auto-negación) de la subjetividad y, por tanto, de la humanitas misma del hombre. Solamente desde esta perspectiva cabe interpretar correctamente un pasaje henryano como el siguiente: "la expulsión de la subjetividad condujo al estrago de la Tierra por la naturaleza asubjetiva de la técnica y, cuando ha sido aplicada al conocimiento del hombre mismo, como en las nuevas «ciencias humanas», ha llevado a la destrucción pura y simple de su humanidad" (Henry 2006, 190). ${ }^{12}$

Esta crucial alusión a la "naturaleza asubjetiva" propia de la técnica muestra claramente que, contemplada desde la perspectiva henryana, la tecnificación contemporánea del mundo deriva del ocaso de la subjetividad viviente propiciado por el pensamiento científico y, a la vez, secunda e hipertrofia este mismo oscurecimiento. Los medios implementados por la técnica no se encuentran ya supeditados a fines externos a ellos mismos, sino que describen un bucle autorreferente que los pone únicamente al servicio de su propia actividad en tanto que medios. Los medios devienen, pues, fines en sí mismos. Con ello, aquello que Henry designa como "fines supremos de la humanidad" o "intereses superiores" del género humano, esto es, los intereses vitales pertenecientes a la esencia de la subjetividad viviente, quedan definitivamente preteridos e ignorados por la naturaleza asubjetiva propia del llamado "progreso científicotecnológico". El dispositivo técnico que opera desarrollándose a sí mismo de forma exclusiva no atiende a otras leyes ni a otras finalidades sino a las propias:

\footnotetext{
${ }^{12}$ En su ensayo Descartes et la question de la technique (1987), Henry apunta al hecho de que los múltiples análisis acerca del fenómeno de la técnica que proliferan el marco del pensamiento contemporáneo, "se pueden ordenar bajo dos rúbricas. Por una parte, aquellos que conciben la técnica como un conjunto de medios cada vez más elaborados, organizados con vistas a obtener ciertos fines que son los del hombre, siendo el progreso la realización de los intereses superiores de la humanidad propiciada por la técnica. Desafortunadamente, la ciencia galileana y la técnica moderna que procede de ella no saben nada de estos intereses superiores de la humanidad en la medida en que su decisión inaugural es la puesta fuera de juego de la subjetividad, o sea, del conjunto de tales intereses. La técnica es, pues, más bien, esto: los dispositivos instrumentales posibilitados por la ciencia de la naturaleza -la cual, por otra parte, se identifica con ellos y debe llamarse tecno-ciencia-; estos dispositivos y sus procesos puramente objetivos no tienen ningún fin distinto de ellos-mismos, es decir, de su propio funcionamiento. Así se produce, fuera de la vida trascendental, fuera de la humanidad, un autodesarrollo de la técnica bajo esta forma" (Henry 2015b, 54-55).
} 
a su lógica inmanente de producción conforme a fines que coinciden con los medios destinados a propiciarlos. El juego de la técnica se juega únicamente en el interior de la propia esfera de lo técnico. En una autosatisfecha interioridad narcisista situada al margen de todo hipotético referente externo susceptible de determinar de algún modo el saber científico que rige la trama de sus procesos. De este modo, también la técnica, en consonancia con la ciencia de la cual deriva, se repliega, al igual que ésta, en una soledad prácticamente absoluta. En este preeminente y exclusivo dominio de la tecno-ciencia sobre cualquier otro posible discurso es donde Henry avizora el auténtico germen de la "barbarie": el fundamento último del proceso de "barbarización" que asola la práctica totalidad de la cultura moderna. ${ }^{13}$

Esta soledad autorreferente propia de la esencia de la técnica ocasiona, además, una decisiva mutación en lo relativo a la concepción misma de la praxis, es decir, al significado de la propia noción de "actividad" en general. La técnica disloca -en sentido etimológico- la praxis desgajándola de su locus "natural" (la subjetividad que expresa las exigencias vitales inmanentes) para trasladarla a un ámbito que por esencia le resulta ajeno: la esfera de la objetividad. En principio, según Henry, la tékhnē aparece originalmente como un modo de actividad práxica derivada de la vida subjetiva y determinada enteramente por ella a través de la ejecución y el efectivo cumplimiento de los poderes del cuerpo subjetivo. Esta expresión de la subjetividad viviente corporalmente encarnada supondría, así, el embrión primigenio de toda forma cultural. Es por ello que en las llamadas "formas superiores de la cultura" (arte, religión, etc.), que al decir de Henry también constituyen modalidades de la tékhnē, la huella de la vida subjetiva en la actividad práctica se halla apreciablemente presente, dado que tales formas se muestran como expresiones inmediatamente derivadas de la subjetividad viviente que las engendró.

No sucede lo mismo tras el sesgo "objetivista" que la modernidad científica y cultural imprime al propio concepto de praxis. En virtud de tal giro teórico y práctico, la actividad en general, la praxis individual y colectiva, comienza a desligarse progresivamente de su naturaleza original: aquella consistente en

\footnotetext{
13 Un fenomenólogo tan distinto a Henry como Jan Patočka apunta, en su ensayo "La supercivilización y su conflicto interno", a una concepción de la barbarización técnica llamativamente cercana a la sostenida por el pensador galo. En referencia a la crisis del mundo antiguo y a su analogía con la situación actual, Patočka escribe al respecto: "El peligro de una barbarización interna no viene dado esta vez por una regresión hacia la ruralización y al estado primitivo (frente a esto la civilización moderna se encuentra protegida por su carácter industrial), sino por la hipertrofia de la misma civilización técnica, por la tecnificación absoluta y la planificación total, que de la naturaleza pasan a aplicarse al hombre, originariamente fin y sujeto" (Patočka 2007, 139).
} 
servir como cauce expresivo a las facultades inherentes a la subjetividad viviente absoluta. Con ello, la praxis experimenta un proceso definitivo de dislocación, desarraigándose de su tradicional morada originaria (la mismidad del sujeto) e injertándose a partir de entonces en el reino del horizonte mundano externo a las demandas vitales que anteriormente la determinaban. Ahora, por tanto, la acción, la praxis, no acontece en la región de la subjetividad creadora de formas culturales transidas de vitalidad, sino en el marco del dispositivo tecno-industrial "objetivo" que actúa de espaldas y al margen de toda referencia a la esencia de lo humano. Henry se refiere a esta metamorfosis "objetivista" de la praxis operada por la ciencia moderna en términos de "conmoción ontológica", es decir, de tránsito revolucionario desde una noción de la acción constitutivamente vinculada a lo humano y subjetivo a un concepto de la praxis ligado esencialmente a la inhumanidad propia de los procesos técnicos extraños a la subjetividad viviente individual. ${ }^{14}$ En la culminación de tal proceso se consuma y cumple el acontecimiento decisivo de la visión moderna del mundo: la deriva que conduce desde lo humano a lo inhumano. Ahora la praxis, otrora vehículo privilegiado de expresión de la subjetividad, deviene instancia objetiva, radicada en el mundo externo al sujeto y encarnada en la tupida trama de relaciones que configura la red del universo tecnificado a escala planetaria. ${ }^{15}$

El soslayo de los aspectos vitales ligados a lo subjetivo y la transformación de la praxis individual en proceso tecno-industrial objetivamente dado, constituyen, pues, los dos aspectos esenciales que ponen palmariamente de relieve el modo en el cual la técnica aparece, desde la óptica abierta por Henry, como instancia antagónica a aquella subjetividad viviente que constituye el más

\footnotetext{
${ }^{14}$ En palabras de Paredes Martín: "La subversión que lleva a cabo la técnica moderna no sólo afecta a la acción sino además a la relación entre el hombre y el mundo. En la apropiación original de la vida y del universo, que tiene su principio en la vida y cuya actualización es el trabajo viviente, la subjetividad tiene el universo en su mano. En cambio, lo que hace la técnica moderna es eliminar de esta relación primitiva la subjetividad, la acción humana en cuanto tal, y sustituirla por procesos objetivos insensibles" (Paredes Martín 2010, 118).

15 Una trama técnica de la cual, como observa acertadamente Henry en Du communisme au capitalisme, no escapa en absoluto el planificado universo social propio del comunismo. Bien al contrario, comunismo y capitalismo coinciden esencialmente en la común factura de una urdimbre de relaciones definidas por la objetividad y por el consiguiente soslayo de la individualidad viviente que ella comporta: "Comment ne pas remarquer l'affinité qui s'instaure entre les régimes qui visent à une planification exhaustive et rationelle de la société, prétendant s'édifier sur la connaissance objective de tous les phénomènes sociaux et matériels dont ils s ímaginent que cette société est la synthèse, et la technique moderne, complexe de processus matériels arrachés à la nature et régulés par cette même connaissance géométrico-mathématique d'où toute subjectivité est évacuée? Le communisme est un rationalisme radical, la première tentative systématique non pas de penser rationnellement mais de régler l'activité humaine comme s'il s'agissait d'un système de relations objectives, d'un objet pur en quelque sorte, étranger à la vie" (Henry 2008a, 220-221).
} 
profundo núcleo ontológico de lo humano. Conviene, sin embargo, reparar en que esta radical oposición entre las respectivas esencias propias de la técnica y de la subjetividad se opone de modo tácito al modo en el que la relación entre ambas es tematizada en el marco de ciertos discursos contemporáneos al respecto. En efecto, la reflexión contemporánea acerca de la técnica -pensamos singularmente en aquella llevada a cabo por Heidegger y sus epígonos- nos ha habituado a considerar el fenómeno de lo técnico en términos de consumación de un determinado modo de considerar lo existente como tal y en su totalidad. La técnica, más allá de su banal identificación con los dispositivos "materiales" o "mecánicos" en los cuales se encarna, constituiría fundamentalmente, según Heidegger, un modo de "desvelamiento" (Unverborgenheit) de lo existente. Aquel bajo cuya mirada la totalidad de lo ente comparece como un ámbito permeable a la "provocación" (Herausforderung) representada por la voluntad de extraer el máximo volumen de beneficio y provecho de un ámbito contemplado ya como mera "objetividad" situada ante un sujeto cognoscente definido además por la voluntad de poder. ${ }^{16}$

Cuando Heidegger habla de la técnica como "metafísica consumada", se refiere particularmente a un tipo concreto y definido de metafísica históricamente acontecida, a saber: la "metafísica de la subjetividad" instituida por el cartesianismo en el instante fundacional de la época moderna. Conforme al prisma ontológico establecido por la nueva "filosofía de la subjetividad", la certeza de la propia mismidad subjetiva descubierta en el cogito cartesiano se erige como puntal metafísico de la totalidad de lo real, mientras que el ámbito natural trascendente a ese fundamentum inconcussum veritatis deviene ahora mera objetividad susceptible de ser representada por el sujeto y acaso dominada por él. ${ }^{17}$ De este modo, la antigua phýsis que acogía en su seno tanto a los hombres como a los dioses incluyendo y conteniendo en sí la totalidad de lo existente, deviene ahora simple "imagen"; espectáculo situado ante la mirada de un sujeto que lo contempla y representa en cierto modo desde el exterior. De ahí que Heidegger, en un célebre ensayo, se refiera a la modernidad caracterizándola como Zeit des Weltbildes ("época de la imagen del mundo"), puesto que expresiones como Weltbild o Weltanschauung únicamente tendrían sentido en el

\footnotetext{
16 "El hacer salir lo oculto que prevalece en la técnica moderna es una provocación que pone ante la Naturaleza la exigencia de suministrar energía que como tal pueda ser extraída y almacenada" (Heidegger 1994, 17).

17 "Esta objetivación de lo ente tiene lugar en una re-presentación cuya meta es colocar a todo lo ente ante sí de tal modo que el hombre que calcula pueda estar seguro de lo ente o, lo que es lo mismo, pueda tener certeza de él [...]. Lo ente se determina por vez primera como objetividad de la representación y la verdad como certeza de la misma en la metafísica de Descartes" (Heidegger 1995, 86).
} 
interior de un modo de pensar en el cual lo que propiamente "hay" es un sujeto autónomo y autosubsistente que se representa un mundo "externo" heterogéneo a sí mismo. Un mundo convertido ya en "objeto", es decir, en ob-iectum o Gegenstand: en algo "arrojado" ahí afuera frente a la subjetividad y que hace frente a ésta o se sitúa en relación de "contraposición" (ob, Gegen) a ella.

Convertido ya en simple "depósito" (Bestand) de "existencias", el mundo objetivo se encuentra plenamente dispuesto para desempeñar el rol de descomunal almacén de recursos puesto al servicio de una subjetividad hegemónica y dominadora. Subjetividad cuya voluntad de poder (no solamente de "representación") es cumplidamente atestiguada, según Heidegger, por indicios tales como la presencia del appetitus al lado de la perceptio en la constitución esencial de la mónada leibniziana o la determinación del fondo primigenio de lo real como Sehnsucht ("ansia", "deseo") y querer originario (Urwollen) en el Freiheitsschrift schellinguiano de $1809 .{ }^{18}$ Observada bajo esta luz, la final determinación nietzscheana de la esencia de todo lo existente en términos de "voluntad de poder" no constituiría sino la apoteósica culminación de la tendencia -originalmente inaugurada por la moderna metafísica de la subjetividad- orientada a situar a ésta en un plano de absoluta preeminencia en el concierto general del Ser. De este modo, la técnica expandida a escala planetaria se mostraría como la más relevante consecuencia del primado concedido a la subjetividad -tanto representativa como volente- por el pensamiento moderno y contemporáneo. Esta necesariamente somera caracterización de la concepción heideggeriana acerca de la esencia de la técnica muestra ya claramente sus divergencias con respecto a las intuiciones apuntadas al respecto por la crítica cultural facturada por Henry.

En efecto, lejos de constituirse como cenit de la tendencia a afirmarse a sí misma por parte de la subjetividad, la técnica aparece en Henry como una instancia tendente a todo lo contrario. La tecnificación del mundo da cumplido testimonio del modo paradójico en el cual la subjetividad, raíz última de toda técnica, se sitúa en los confines del olvido de sí, en su máximo grado de autoocultación y alienación con respecto a su esencia más propia. Late aquí la cuestión relativa a la extraña ambigüedad que acompaña permanentemente al

18 "El principio, hasta donde procede del fundamento y es oscuro, es la voluntad propia (Eigenwille) de la criatura, la cual, sin embargo, hasta donde todavía no se ha elevado [...] a la perfecta unidad con la luz [...] es mera pasión (Sucht) o concupiscencia (Begierde), es decir, voluntad ciega (blinder Wille) [...]. La voluntad del hombre es el germen, oculto en el ansia eterna (ewigen Sehnsucht) del Dios que sólo subsiste todavía en el fundamento; es el rayo de vida divino aprisionado en la profundidad, que Dios percibió cuando concibió la voluntad para la naturaleza" (Schelling 1989, 174177). 
fenómeno de la técnica ¿Cómo es posible que la técnica devenga elemento "asubjetivo" y favorecedor del olvido de sí por parte de la ipseidad viviente cuando resulta palmario que se trata de una instancia cuyo origen resulta únicamente localizable en el interior de esa misma subjetividad vital que en tan decisiva medida contribuye a ocultar y difuminar? ¿Pone acaso de relieve este carácter ambiguo y paradójico ligado a lo técnico una larvada contradicción localizada en el núcleo mismo de la subjetividad? Porque tal vez el sorprendente hecho de que la técnica propicie el olvido de sí por parte de la subjetividad, como apunta Henry, obedece en último término a la tácita voluntad del sujeto de librarse de la onerosa carga representada por la individualidad plenamente consciente de sí misma. Parece como si los inesperadamente endebles hombros del sujeto moderno flaqueasen a la hora de sostener el gravamen representado por su propia condición de nuevo hypokeímenon llamado a actuar como fundamento epistémico de la totalidad de lo existente. Desde este punto de vista, la técnica admitiría ser contemplada como el instrumento objetivo que el sujeto pone en juego con el fin de evitar serlo: con objeto de ocultarse a sí mismo las implicaciones negativas e inquietantes derivadas de su propia condición. La objetividad perseguida por la ciencia y la técnica modernas se mostraría, de este modo, como síntoma inequívoco de la huida de sí misma que la subjetividad emprende en dirección a aquello que esencialmente ella misma no es. En dirección a su determinación opuesta. Esta es, a nuestro juicio, la intuición que cabe inferir de las premisas conforme a las cuales Henry describe la negación de la subjetividad viviente por parte de aquellas instancias que, como la ciencia y la técnica, tienen necesariamente su génesis en ella. ${ }^{19}$

$\mathrm{Y}$, sin embargo, hay un aspecto -tal vez menos conocido- de la meditación heideggeriana acerca de la técnica que sí entronca por extraños caminos con la caracterización "antisubjetiva" que Henry, como acabamos de ver, ofrece de ésta. Se trata de la intuición según la cual en el propio seno del Ge-stell, del "dispositivo" de "emplazamiento" o "im-posición" en el que cristaliza la esencia de la técnica, "vemos un primer y persistente destello (Aufblitzen) del Ereignis" (Heidegger 2006, 47): del "evento de apropiación" en el cual el hombre y el Ser entran en relación de "copertenencia mutua" (Zusammengehörigkeit), perdiendo

\footnotetext{
${ }^{19}$ Siguiendo su particular interpretación de Marx, al cual considera una especie de teórico de la subjetividad viviente y activa, Henry escribe al respecto que "La mutation des forces productives qui va commander le destin du monde moderne doit alors se formuler comme suit: la subjectivité -le travail vivant- se trouve progressivement éliminée du procès réel de production tandis que la part en lui du dispositif instrumental objectif ne cesse de grandir. Ou encore: le procès de travail et le procès de production divergent, ce qui est une autre façon d' exprimer le dépérissement de la forcé subjective de travail dans un procès livré à une objectivité croissante" (Henry 2008a 161).
} 
así los respectivos estatutos de "sujeto" y "objeto" que les había adjudicado tradicionalmente la metafísica. En la entrevista concedida por Heidegger a Der Spiegel y publicada póstumamente, el sentido de esa insospechada convergencia entre técnica y donación del Ser se torna explícita cuando Heidegger afirma que "El imperio de la «im-posición» [Ge-stell] significa: el hombre está colocado, requerido y provocado por un poder, que se manifiesta en la esencia de la técnica. Precisamente en la experiencia de que el hombre está colocado por algo, que no es él mismo y que no domina, se le muestra la posibilidad de comprender que el hombre es necesitado por el ser. En lo que constituye lo más propio de la técnica moderna se oculta justamente la posibilidad de experimentar el ser necesitado y el estar dispuesto para estas nuevas posibilidades" (Heidegger 1989, 72-73). Heidegger y Henry convendrían, pues, en reconocer un carácter esencialmente "antisubjetivo" a la técnica: bien larvado y potencial (Heidegger), bien explícito y actual (Henry). Así, desde la óptica de Heidegger, la técnica, a pesar de sus originarias raíces "subjetivas", representa esencialmente una chance orientada a propiciar una suerte de preparación propedéutica merced a la cual el hombre -ya no el "sujeto"- aprende a aceptar la prioridad de la donación del Ser como instancia supraindividual que precede a toda subjetividad. La filosofía ayudaría a comprender esto y "no puede hacer más" $(1989,73)$. Por su parte, Henry contempla el fenómeno de la técnica, como hemos visto, en términos de máxima objetivación del deseo de olvido de sí misma por parte de la subjetividad viviente. Ambos pensadores convergen, pues, al intuir comúnmente el constitutivo sustrato supra-subjetivo subyacente a la esencia de lo técnico, pero divergen en sus respectivas valoraciones al respecto de tal "hecho": potencialmente "positiva" por parte del filósofo de Messkirch y abiertamente "negativa" en el caso del fenomenólogo galo.

Retomando las tesis apuntadas por este último, la técnica aparecería, en cualquier caso, como una monumental pantalla mediadora: como un dispositivo objetivo proyectado por el sujeto, pero destinado precisamente a alienar a la subjetividad de su propia esencia en tanto que instancia eminentemente viviente. $^{20} \mathrm{Y}$ en este contexto, obviar la propia vida relegándola a la nada equivale a negarla de forma radical. Henry se refiere a esta paradójica forma de

\footnotetext{
${ }^{20}$ En Voir l'invisible, en referencia al papel jugado por los mass media en el contexto de la civilización tecnificada, Henry apunta al respecto la siguiente observación susceptible de ser aplicada a la esencia propia de la totalidad del mundo técnico: "Sucede solamente que el hombre de nuestro tiempo no tiene ya nada de popular, de espontáneo, de instintivo, de real, de vivo. Una mediación ha venido a separarlo de sí mismo, precisamente la de los medios de comunicación que sustituyen en todas partes el libre juego de la vida y su sensibilidad por la copia de un universo irreal, artificial, estereotipado, envilecedor, en el que la vida, en lugar de realizarse, no puede ya sino huir" (Henry 2008b, 92).
} 
autonegación de la vida en el marco de la cultura nacida de la modernidad del siguiente modo: "He aquí, pues, una forma de vida que se vuelve contra la vida, rehusándole todo valor, cuestionando hasta su existencia. Una vida que se niega a sí misma, la autonegación de la vida: tal es el acontecimiento crucial que determina a la cultura moderna como pura cultura científica" (Henry 2006, 94). Pero, cabría cuestionar, ¿cuál es la razón última por la cual la subjetividad viva decide darse a sí misma la espalda a favor de una reificación que por esencia no le conviene, dado que contradice su más íntima naturaleza? Trataremos seguidamente de elucidar, a la luz de la crítica henryana de la cultura, las causas de esta llamativa contradicción de la vida consigo misma en el seno de la cultura moderna.

\section{El olvido tecno-científico de la subjetividad como olvido voluntario}

El proyecto de eliminación de la subjetividad viviente tácitamente contenido en la estructura misma de la ciencia moderna surgida de aquélla obedece, según Henry, a la presencia de un "secreto descontento" alojado en lo más profundo del espíritu moderno: "un descontento que es el hecho de la vida, en la medida en que es ella la que quiere esa eliminación, un descontento a propósito de sí misma, en la medida en que lo que quiere eliminar es a sí misma" (Henry 2006, 104). La tendencia a perderse a sí misma en lo objetivo que muestra la subjetividad moderna denota la inquietante sombra de una profunda desavenencia interna inserta en la propia médula de lo vital. El sujeto autónomo y autoafirmado surgido de la cultura moderna se halla, pues, desazonado consigo mismo, y el padecimiento negativo derivado de tal descontento se traduce en voluntad de deshacerse de sí con el fin de mitigar ese sufrimiento. Ciencia y técnica constituyen, pues, sendos instrumentos objetivos cuya función consiste esencialmente en oscurecer esa vida subjetiva que se adivina como sede privilegiada del sufrimiento. La propia subjetividad viviente los crea con tal fin: hacer cesar el padecimiento obturando su fuente de origen.

Sin embargo, la tragedia de la cultura moderna consiste precisamente en que la voluntad de negarse a sí misma por parte de la vida subjetiva constituye, en última instancia, una empresa quimérica. Desde su primera gran obra, L'essence de la manifestation, Henry insiste en una concepción de la subjetividad entendida como pura inmediación patética que se auto-afecta al margen de toda referencia al horizonte "ek-stático" marcado por el mundo objetivo. Una vida que se afecta a sí misma en el "pathos de su noche", ajena por completo a la objetividad 
externa a sí. $^{21}$ Esta auto-donación en la que consiste esencialmente la vida implica que todo contenido afectivo (Henry habla al respecto de la desesperación y de la dicha) se da con una pasividad absoluta. Tal cosa significa que el sujeto no es capaz de actuar sobre sus propias afecciones, dado que éstas se muestran como elementos totalmente independientes de todo factor ajeno a su propia naturaleza. Así, un sentimiento como, por ejemplo, la desesperación aparece a esta luz como "profundamente indiferente a las circunstancias que la rodean o que la han visto nacer, de modo que no puede ser modificada por ellas, que no se puede actuar sobre ella, provocarla o suprimirla, actuando sobre éstas, buscando, por ejemplo, modificar su curso en un sentido favorable a las aspiraciones del sujeto" (Henry 2015a, 468). Si observamos con agudeza, esto es justamente lo que sucede en el caso de la subjetividad moderna que trata de librarse de su sufrimiento y descontento interno (afecciones tan inmodificables como todas las demás) mediante el recurso a la objetividad propia de la tecno-ciencia.

Pero, dado que resulta imposible practicar una cesura radical entre la subjetividad y sus afectos inmanentes -el descontento y el sufrimiento incluidos-, la tentativa moderna de negación de la vida subjetiva mediante la introducción de dispositivos objetivos que la eclipsen se halla por esencia abocada al fracaso. ${ }^{22}$ Es más, conforme al dictamen de Henry, cuanto mayor es la voluntad de escindir a la vida subjetiva de sus afecciones, más se fortalece el vínculo que vincula a ambas instancias. La auténtica indigencia propia de la subjetividad moderna radica no sólo en el hecho de no soportarse a sí misma y en el consiguiente deseo de huir de sí, sino fundamentalmente en la frustración resultante de la imposibilidad de consumar con éxito tal pretensión. Esta imposibilidad de dejar atrás su sufrimiento negándose a sí misma a través de la objetividad vinculada la ciencia y la técnica, propicia el hecho de que la subjetividad moderna contemple cómo tal sufrimiento se reafirma y crece alimentado a partes iguales por el deseo

\footnotetext{
${ }^{21}$ Así, "Loin de demander à la pensée objective de la rendre manifeste, la vie accomplit elle-même l'oeuvre de sa propre Révélation et cela en tant qu'elle s'éprouve elle-même dans la certitude invincible de son besoin, de son effort, de sa souffrance ou de sa joie. Elle seule échappe au doute puisque, selon l'intuition générale et décisive de Descartes, quand bien même le monde n'existerait pas, n'étant qu'un songe, elle n'en subsisterait pas moins, telle qu'elle s'éprouve" (Henry 2008a, 218).

${ }^{22}$ La razón última de este fracaso nacido de la imposible pretensión de escapar a la propia vida es explicitada abiertamente por Henry en los siguientes términos: "C'est précisément parce que la vie n'a pas le pouvoir de se mettre réellement à distance de soi qu'elle ne peut échapper à soi ni par exemple à sa faim, à sa souffrance, à son angoisse. C'est aussi la raison pour laquelle le moi, l'individu vivant est impuissant à se défaire de sa vie, à donner en quelque sorte congé à ce qu'il éprouve" (Henry 2008a, 46).
} 
redoblado de escapar de él y por el sentimiento de impotencia ligado al continuo naufragio de ese deseo.

La constatación constante de lo quimérico de su proyecto aboca finalmente al sujeto moderno a la angustia derivada del sentimiento de sí mismo como imposibilidad de huir de sí y de sus propias afecciones negativas. La técnica, y con ella el saber científico que la fundamenta, se muestran, pues, como medios a través de los cuales la vida subjetiva persigue mitigar y lenificar esa angustia en la medida de lo posible, formulando a la vez una tan improbable como irrenunciable promesse de bonheur proyectada hacia el futuro. ${ }^{23}$ De este modo, la hipertrofia contemporánea de la técnica testimonia tanto el deseo de la humanidad de huir de sí misma, como su falta de resignación a la hora de constatar el carácter irrealizable y utópico que reviste tal propósito. La desatinada contumacia con la cual la técnica no cesa de producir nuevos medios tendentes a atemperar toda angustia y a favorecer en el mayor volumen posible la felicidad individual, atestigua por sí misma la profunda contradicción de fondo sobre la que se asienta la totalidad del moderno mundo tecnificado. Es desde esta óptica como cabe comprender, a nuestro juicio, las observaciones de Henry relativas al hecho de que el desarrollo excesivo de la dimensión tecno-científica en la época moderna no constituye sino un formidable intento mediante el cual la humanidad trata de paliar la angustia ligada a su descontento de sí misma. ${ }^{24} \mathrm{Se}$ trata de observaciones como la siguiente: "Es necesario considerar el hiperdesarrollo de la ciencia moderna como una de las tentativas mayores por las que la humanidad ha emprendido la tarea de huir de su angustia. ¿No resulta extraño que, si la vida es por esencia el experimentarse a sí misma y el sentirse a

\footnotetext{
${ }^{23}$ Y, no obstante, ya en L'essence de la manifestation, Henry advierte acerca del carácter quimérico propio de semejante pretensión: "El conjunto de las técnicas por las que los hombres transforman el mundo y lo adaptan a su conveniencia puede mucho, pero absolutamente nada, como bien sabemos, en lo que concierne a la dicha; de manera que el intento de provocar ésta sólo conduce a la multiplicación de los medios utilizados para este fin, a la invención incesante de nuevas técnicas de felicidad cuya proliferación insensata en el mundo moderno manifiesta únicamente su total impotencia en cuanto al resultado pretendido" (Henry 2015a, 469).

${ }^{24} \mathrm{Al}$ menos en este aspecto, la crítica henryana a la tecno-ciencia entronca estrechamente con la reflexión acerca de la esencia de la técnica llevada a cabo por Emanuele Severino. Considérense al respecto pasajes como el siguiente: "Incominciamo a dire che abbiamo tutti esperieza del dolore. Essere uomini significa avere coscienza del dolore. Quando l'uomo tenta di liberarsi dal dolore -e lo fa da quando lo sperimenta, cioè da quando vive- escogita rimedi contro il dolore. La verità e la tecnica sono i grandi rimedi escogitati dall'Occidente" (Severino 2003, 25). De hecho, desde la perspectiva adoptada por Severino, la técnica moderna se revela en su más profunda esencia como un "medio", un privilegiado "instrumento" (tal vez el más eficaz de cuantos ha logrado forjar la cultura occidental) destinado a conjurar y remediar la angustia provocada por la imprevisibilidad ligada al devenir del mundo.
} 
sí misma de una pura subjetividad, veamos nacer en ella una intentio que, considerada constitutiva del saber, consiste precisamente en rechazo de esta esencia de la vida?" (Henry 2006, 105).

\section{Conclusión}

A modo de conclusión, señalemos que la crítica de Henry a la tecno-ciencia reviste el sentido de familiarizarnos con la idea de que la cultura fundamentada sobre ésta, lejos de constituir paroxismo de la subjetividad alguno, representa inversamente el apogeo del olvido de sí: "la nueva barbarie, cuyo saber específico y triunfante paga el precio más elevado, la ocultación por parte del hombre de su ser propio" (Henry 2006, 106). Conviene subrayar esta intuición teniendo en mente aquellos discursos actuales que deploran tan reiterada como irreflexivamente el supuesto "individualismo" y el presunto "subjetivismo" que según su dictamen- impregnan por doquier la totalidad de las expresiones propias de la cultura occidental contemporánea. Discursos que, por lo demás, hallan su antecedente y fundamento más remarcable en la interpretación heideggeriana de Descartes y Nietzsche como respectivos inicio y consumación de la subjetividad entendida como "voluntad de poder". Dígase algo análogo en referencia a la observación de Henry conforme a la cual, desde el punto de vista de la ciencia que únicamente conoce y admite "objetividades", la interioridad subjetiva -es decir, la vida- simplemente "no existe": "En el campo abierto por la ciencia galileana hay cuerpos materiales, partículas microfísicas, moléculas, cadenas de ácido, neuronas, etc., pero no hay ningún Sí. En el campo abierto por la ciencia moderna no hay ningún hombre" (Henry 2001, 300-301). Esta intuición nos conduce a relativizar y restringir la capacidad que el discurso científico culturalmente imperante -singularmente aquel ligado a la biología- puede legítimamente arrogarse a la hora de hablar acerca de nuestra vida efectiva y realmente existente (verdaderamente vivida). Esta vida trascendental e inmanente resultará siempre inaccesible para la biología científica por su misma esencia, resultando únicamente permeable a la mirada propia de la fenomenología. ${ }^{25}$ A la penetración de un discurso que no atiende

\footnotetext{
${ }^{25}$ Así, en C'est moi la verité, una sus últimas obras, Henry escribe al respecto: "ahora, cuando la biología logra sus avances más decisivos, hay cada vez más ignorancia respecto a lo que realmente es la vida; que, lejos de implicar sólo a la biología, esta ignorancia se extiende a la totalidad del campo de los conocimientos científicos y que éstos, sobre todo por el culto que se les rinde, terminan impregnando por completo el espíritu público [...]. La puesta entre paréntesis de la vida por la decisión galileana que inaugura la ciencia moderna concierne en primer lugar a la biología. Es en su
} 
fundamentalmente a lo que se da (como objeto), sino al modo en que ello se da y manifiesta (como acontecimiento).

A la vez, la crítica henryana también cuenta con el mérito de recordarnos que la noción de "progreso", tan invocada en nuestro contexto cultural en el cual ha devenido ya dogma, no designa de forma exclusiva el progreso de orden científico-tecnológico, sino que remite esencialmente a aquel progreso moral y espiritual cuya morada se halla en la subjetividad viviente individual. Especialmente en aquella perteneciente a las individualidades antaño designadas como "geniales" y que hoy asumen el dudoso estatuto de "singularidades" o "excepciones" con relación al tipo comúnmente aceptado. Un tipo de progreso consistente en el favorecimiento del desarrollo autónomo de las diversas facultades vitales y culturales constitutivas del espíritu humano. En referencia a estos dos conceptos contrapuestos de "progreso", Henry escribe: "La noción de progreso ha llegado de este modo a designar de manera exclusiva el progreso técnico. La idea de un progreso estético, intelectual, espiritual o moral, con sede en la vida del individuo y consistente en el autodesarrollo y el autocrecimiento de las múltiples potencialidades fenomenológicas de esta vida, en su cultura, ya no tiene vigencia, al no disponer de ningún lugar asignable en la ontología implícita de nuestro tiempo, según la cual no hay más realidad que la objetiva y científicamente cognoscible" (2006, 82). Uno de los dogmas fundamentales de nuestro tiempo posee, en este sentido, raíces ontológicas ocultas; una raigambre de orden "metafísico" que el análisis crítico henryano se encarga de explicitar, sacar a la luz y tornar manifiesta. En este sentido, la propuesta formulada por el fenomenólogo francés favorable a la idea de "progreso" entendida como despliegue de las potencias vitales latentes del individuo, constituye acaso una de las más destacadas apologías de los poderes propios de la subjetividad particular en el marco de la fenomenología actual y, por extensión, en el panorama general del pensamiento contemporáneo.

\footnotetext{
campo donde manifiesta su efecto más notable, orientando la investigación hacia los substratos químicos y físicos de los fenómenos biológicos y de su funcionamiento específico. Es una consecuencia absolutamente necesaria que al término de tal investigación no se encuentren sino procesos físico-químicos y nada que se asemeje a la experiencia interior que cada viviente tiene de su vida [...]. Los biólogos, ellos sí saben qué es la vida. No lo saben como biólogos -puesto que la biología no sabe nada de esto-. Lo saben como todos nosotros porque también ellos viven, porque aman la vida, el vino, las mujeres, porque aspiran a un puesto, hacen carrera [...]. Pero esas sensaciones y emociones, ese creer, esa ventura o el resentimiento, todas estas experiencias o aflicciones que son otras tantas epifanías de la vida, no son a sus ojos más que "pura apariencia»" (Henry 2001, 46-49).
} 


\section{Referencias bibliográficas}

Audi, P. (2006). Michel Henry. Une trajectoire philosophique, Paris, Les Belles Lettres.

Domínguez Basalo, A. (1982-1983). “¿Por Marx y contra el marxismo?: el Marx de Michel Henry", Anales del seminario de historia de la filosofía, 3, pp. 241272.

García Jarama, J. C. (2007). Finitud, carne e intersubjetividad. La estructura del sujeto humano en la fenomenología material de Michel Henry, Toledo, Instituto teológico San Ildefonso.

Heidegger, M. (1989). Escritos sobre la Universidad alemana, Madrid, Tecnos.

Heidegger, M. (1994). Conferencias y artículos, Barcelona, Ediciones del Serbal. Heidegger, M. (1995). Caminos de bosque, Madrid, Alianza Universidad.

Heidegger, M. (2006). Identität und Differenz (GA 11), Frankfurt am Main, Vittorio Klostermann.

Henry, M. (2006). La barbarie, Madrid, Caparrós Editores.

Henry, M. (2008a). Du communisme au capitalisme. Théorie d'une catastrophe, Paris, L'Age d'Homme.

Henry, M. (2008b). Ver lo invisible. Acerca de Kandinsky, Madrid, Siruela.

Henry, M. (2015a). La esencia de la manifestación, Salamanca, Sígueme.

Henry, M. (2015b). Phénoménologie de la vie V, Paris, PUF.

Henry, M. (2001). Yo soy la verdad, Salamanca, Sígueme.

Paredes Martín, M. C. (2010). "Conflictividad y libertad. Una aproximación a la fenomenología social de M. Henry”, Investigaciones fenomenológicas, 7, pp. 99123.

Patočka, J. (2007). Libertad y sacrificio, Salamanca, Sígueme.

Schelling, F. W. J. (1989). Investigaciones filosóficas sobre la esencia de la libertad humana y los objetos con ella relacionados, Barcelona, Anthropos.

Severino, E. (2003). Tecnica e architettura, Milano, Raffaelo Cortina Editore. 
